Saad, S.Kh. (2021). The Human Voice as a Genius Instrument to be trained. Culture and arts in the context of cultural heritage. Klironomy, 3 (3), 7-44. Hlučín-Bobrovníky: “Anisiia Tomanek” OSVČ.

DOI: $10.47451 /$ art2021-10-005

EOI: $10.11249 / \operatorname{art} 2021-10-005$

The paper is published in Crossref, Internet Archive, ICI Copernicus, Google Scholar, Academic Resource Index ResearchBib, JGate, ISI, CiteFactor, Journal Factor, eLibrary, Ukrainian National Library databases.

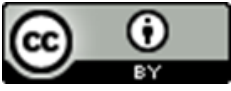

\author{
Salim Khalil Saad \\ Professor, Doctor of Science in Art (Music) \\ Department of Arab East Researches in Music \\ Faculty of Music Sciences \\ Moscow Scientific Research Institute of Art Studies \\ Ain Zhalta, Mont-Liban, Lebanon \\ E-mail: drprofsalimsaad@gmail.com \\ ORCID: 0000-0002-6036-3589
}

\title{
The Human Voice as a Genius Instrument to be trained
}

\section{Abstract:}

The professionalism of the Voice is the ability to control the human voice in order to activate and use it with all its expressive and influential capabilities. Voice control means learning it through analysis and theoretical and scientific analysis, and then installing it with the desired or proposed template from the student and analyst to give him the best cases in expression. This means submission to the state of training and practice of human voice with all its various data and points of performance, and, thus, the establishment of a methodology and schedule suitable for a professional purpose, scientifically applied (Scientifique - pratique) or inborn (Naturel experimental). The former shortens the time devoted to professionalism, while the latter takes longer to increase productivity and remains free from the analysis and science that the former includes. Academic experience today has confirmed that each scientific phenomenon creates its own science and knowledge and becomes open for teaching at the university and specializes in its work and professionalism. And when knowledge precedes what is known about it, it reduces time and reduces the difficulties of confrontation. Therefore, the professionalism of its first type (scientific and applied) became the prerogative of science, its institutes and universities, without discarding the second type (innate - experienced). The two together is the best goal, and if we prefer between them, then our choice is based on the first according to scientific preference.

Keywords:

voice, human voice, practice, speech, voice expression, academic voice, natural voice, diction, phonetic, oratory, singing. 


\section{Physical and expressional structures of the Human Voice}

A big question arises: is human voice being analyzed? And the answer: yes, in general, as any moving and active mechanism consisted of several elements. It is also possible to analyze liquids and install new liquids or objects from its elements. Also, a car engine can be dismantled and reinstalled in a way that differs from its previous shape, that is, by improving its shape and performance.

So, what makes up a human voice? we can say that the human voice has two structures: the first is physical, and the second is the expressional.

The first, physical, contains:

- Lungs storing air,

- Throat sounding under the air - exhale,

- Throat, inside of mouth and cheeks and nasal cavities.

The second, expressional consists of:

- Ton degree,

- $\quad$ Strength (Dynamic),

- Vocal accent or start (Attaque),

- Vocal Density (Compressed Diaphragm),

- $\quad$ Speed (Velocity),

- Voice and emotional state (Feeling),

- Voice Timber.

All these elements are subject to change and control, with the exception of the voice timber or voiceprint, which remains like a fingerprint of a person, the main characteristic of a person through his phonetic personality. However, it undergoes distortion or some changes when manipulating the voice start (Attaque) or the beginning, since the opening of the throat, the amount of air and the speed of collision with the throat occur due to what is called a change in the timber type of the voice, as we will see later in this study.

Tonal degree of voice: Tone is the pitch of a sound or voice, updated by a constant number of vibrations. And this score may not coincide with any of the steps of the musical scale, whether in major, minor, diatonic or chromatic. Or it may belong to a musical scale or correspond to one of its degrees. This is due to the limitation of the musical tonal system, which generally does not work with phonemic ratings.

Accordingly, we confirm the existence of two main types of phoneme scales: musical tonal scale (Échelle tonale musicale) and absolute non-musical expressive scale (Échelle éxpressive absolue atonale). The first one is limited to music and singing, the second one contains music and singing and any vocal sound. And the 
absolute form of scale is not common in phonological science, because it has not been studied, researched and organized to this day, because of the difficulty of its non-measured degrees and its extensive involvement, on the one hand, and its neglect, relying on education without knowledge and application on the other hand.

Vocal professionalism is just a training to create voice on any degree, musical and non-musical. Voice training has two types:

1) Sing music with words or lyrics (songs) or without (vocalize) in vowel letters: A O U E ...;

2) Issue a voice with and without words at all degrees.

Thus, the diversity and multiplicity of exercises of the human voice are automatically classified according to the so-called exercise, etude, piece, then the voice art project and vocal work (Oeuvre). And we will deal with all this in detail and will accompany it with the necessary exercises and performances, which must be applied and repeated for the sake of professionalism. Each phoneme has its own volume of exhaled air when released, the higher degree, the less expiration is required.

Vocal Power-Dynamics (Dynamique): This is the second immediate component that follows the degree with its vocal importance, without it there is no vibration and no voting. And vocal power also imposes itself on any sound that occurs. And if we can change the vocal power, we can change the expressive meaning of the sound, even if the vocal pitch remains unchanged.

Vocal start (Attaque): This is the main center for making sound, as it is caused by an exhalation restriction (compression) and is then released. The more compressed exhalation of air is compressed, the stronger vocal start is done. Exhalation capture is important immediately, as is the ability and flexibility of the air nozzle, that is, the air valve located in front of the throat. There are types of people whose talents differ in this, for example, their difference in faces, strength, speed of movement, shape of fingerprints, etc.... Thus, physical exercises also differ for different people depending on the needs of each of them. since some of them have more vitality in the air valve than others.

Vocal performances are mainly based on the vocal start of all types and genres of vocal performers. We cannot but notice the problem of the belief that vocal practice seems to be an urgent need for singers, and not for preachers, poets, broadcasters and actors. This has its main reasons, the most important of which is that a person, whether a singer or an orator, practices speech much more than singing. And this percentage seems to be distributed at 10\% for singing and $90 \%$ for speech and its genres. 
Thus, lyrical performance consists of three types of performers and at three levels, namely:

1. Singer who plays perfectly the melody with impeccable tonal stability and has not the linguistic skill or the art of voting and the art of linguistic sound.

2. Vocalist with limited voice timber and performing a melody with minimal quality, not possessing the art of vocalization, but rather owning a linguistic pronunciation.

3. Professional Singer, who enjoys good quality, qualitatively performs the melody, with mastered voice, speaks the language with all its zigzags, and the language does not tolerate submission to any expressive vocal performer or a preacher, poet, a good actor or other artists.

And we mention the international singer Julio Iglesias of Spanish descent, even in his language, and he does his work in French, which insulted him and instituted criminal proceedings against him from the French authorities because of this insult to the French language. But the aesthetics of his melodic, lyrical and sensual performance made him a pretty international singer. Therefore, in our opinion, Julio Iglesias does not master the vocal art, but rather masters the art of limited melodic performance, which, as we have repeatedly stated, is an organized part of the human voice. Here we pay attention to the fact that the correct melody is enough to express the feelings of performer, even if his linguistic performance or principles of voting are not enough. This problem is being imposed today in all parts of the world, where there are many singers and professional singers.

Thus, the following comparative table can be obtained on the basis of the elite type, which, in turn, is subject to different discretions in the elites of its elements and a comparison between them:

Table 1. Comparative table between the three categories of singers

\begin{tabular}{|c|c|c|c|c|c|c|}
\hline $\begin{array}{c}\text { Performer } \\
\text { title }\end{array}$ & \multicolumn{6}{|c|}{ Mark } \\
\hline & Sense & Voice & Spell & Melody & Timber & Rhythm \\
\hline Singer & fair & Medium & excellent & good & fair & good \\
\hline Perfect Singer & excellent & Small & fair & excellent & fair & good \\
\hline Professional & excellent & Perfect & excellent & excellent & excellent & excellent \\
\hline
\end{tabular}

This helps us to adopt clear and tangible scientific standards when classifying vocal performers as singers, chants, full-time singers and others. As we often hear a question among listeners about the differences between this and that of the vocalist singers. Accordingly, we were convinced that we need to create a clear and fair basis 
for evaluating one or another human voice or one or another performative types of voice and singing in general. And in these criteria, which we call the "vocal beginning" or "start-attacks", and we expressed them in the language as one of the criteria for evaluating the voice. Moreover, all professional broadcasters, readers and speakers have mastered and pronounced the phonemic principle, even if they have not mastered the melody, rhythm or other elements of the musical voice.

Here we conclude that the beginning of voice is the basis for creating a full voice that stands out in the language, not in singing. How singing overwhelms this vocal, starting with the aesthetics of the melody. As for the singer or full singing (we will explain later), the vocal beginning (linguistic intonation) and the correct melody should be mastered equally. We also confirm the following equation:

vocal start $=$ proper breathing control + precise larynx vibration.

Acoustic Density: (Velocity), which is closely related to the opening of the airways (i.e., the exhalation valve). Or, in other words, it is a sound that changes the atmosphere. Therefore, we confirm the many and endless situations of opening the throat for one person, so how then are their differences between one person and another? Therefore, they have different situations with different words, accents and phoneme symbols in one language, so how much more is this in several languages. And the opening of the throat, as we have shown through experiments and research, is the three main forms to which the three characteristics apply. And this:

- narrow,

- medium,

- wide.

Three characteristics:

- extreme

- moderate intensity

- lethargy or looseness

Between the first, second and third forms of the opening of the throat there are countless types of sounds. And in a useful summary there are no restrictions for these forms, but we can define the entries for them through the three abovementioned forms and the new forms between them and resulting from them. This can then lead to 3 (three) types of sound intensity in one person for the three main types of sound, namely:

1. Brilliant Voice (La Voix Brillante) with the vowel "A".

2. Dry Voice (Voix Mate) with the word "Ha". 
3. Voice of Buzz (Voix Klaxonnante) (whining or Voice of a clique) with the word "aa" has no equivalent in Latin.

Thus, the number of the minimum number of voices and their types increases unlimitedly, the smallest number is hundreds and possibly thousands. This is in addition to the contribution of the throat aperture to the production of various phoneme letters (Voyelles) in all languages and speeches. In any case, the aesthetic taste varies between people according to these types of voices. However, an approximate consensus remains possible in cases that have become part of familiar and common people, with different people and civilizations, such as beautiful singing, beautiful sayings and voting.

And the intensity of the voice contains the beginning of the types of endless voices, because it is based on an opening that has no limit for the throat and at the same time is flexible and malleable.

And, as before, we confirmed the three main forms of opening the throat and its three characteristics. Therefore, we confirm three cases of the external atmosphere of the lungs as follows:

1 - thin, non-dense, 2 - medium dense, 3 - thick.

Voice speed: the speed of sound has several meanings and interpretations, since sound has several movements, and not one movement that can be accelerated or slowed down. The moving parts of voice are:

1. Speed of the air exit from the lungs, that is, Exhalation rush

2. Speed of the throat movement and of the throat aperture

3. The speed of continuity between linguistic sounds, that is, the acceleration of the discard of a linguistic text or what we call linguistic segmentation or "linguistic rhythm", which is the beginning of a general musical rhythm, as we previously emphasized in our researches

4. The speed of the end of the phoneme, and here we are talking about what is called a linguistic rhythm, whether it be poetry or prose in the same way or "acoustic rhythm". We must explain each of these speeds in their effect on the elements of sound in terms of strength, power, sensation, etc.

Exbalation push: This is the air that flows from the lungs to the outside to shock the throat and make a voice. Regardless of the amount of air and its amount, the exhalation rate remains independent and greatly affects sound, quality, type and general expression. Among the most important effects:

A. Deviation from the phonemic tone, and this causes the so-called "stray" sound or "cacophony". This is due to the fact that an increase in the rate of exhalation or a decrease in it causes a change in the place of collision with the larynx, which 
resembles a dense tendon. We all know that the string larynx sounds with fluctuations of a variable frequency with a change in the point of impact or percussion, such as oud (Lute), violin, canoun, harp, etc.

B. Exhaustion of the air intake in a time that is less than necessary, which leads to weaknesses and shortcomings in performing a vocal task and causes an imbalance in the strength of the voice, and the performance loses its desired expression.

C. Excess or extraction of sound or the alleged linguistic letter, which negatively affects the simultaneous movement of the tongue with the release of exhalation, so that linguistic imbalance or the so-called noise in the voice expression occurs. Ring throat valve: it is a valve whose movement speed varies from person to person, and it is similar to any muscle organ in the human body that can train, exercise and improve performance depending on time, i.e., over a period of time and speed. We called it the isolation valve, because it blocks internal respiration, stops the exhalation and presses it into the lungs in accordance with the expected strength of the sound. That is, he ventilates the venous tendons of the throat directly from the inside out, and not vice versa. This is because of the divine wisdom in protecting a person from suffocation due to the thermal changes of the outside air and the toxic and deadly air, and the dust that the air carries. When the synchronize movement weakens with the necessary voting, the following occurs:

A. Excess or extraction of sound or the alleged linguistic letter that adversely affects the simultaneous movement of the tongue with the exhalation, so that there is a language imbalance or the so-called noise in the voice expression.

B. Part of the compressed air in the lungs is exhaled, which leads to a lack of betterquality indicators.

C. The presence of meaningless and nonsense votes in the voice, whether linguistic or non-linguistic

Linguistic segmentation: this is diction performance and linguistic reading, which is seriously affected by acceleration and deceleration, due to the importance of the temporal time of sounds and language symbols in their clarity and good expression. And to speed up or slow down language segmentation, without any harmony with the text, there are many negative effects, the most important of which are:

A. An expressional deviation from a natural or desired emotional state or sense. An expression can sometimes impose haste to express anger, enthusiasm, and delight ... and sometimes slowly express calmness, sadness, despair, etc.

B. A rhythmic linguistic error that spoils the prestige of the consonants arising from the movement of the tongue and its friction on the jaw and roof of the 
throat. Which contradicts what is called intonation or the rule of linguistic vocabulary. And here is the confirmation of intonation with the phonetics closely and inextricably in all languages. This confirms that we already mentioned language skills and voting for a good speaker, a good vocalist, a good singer, and a good actor. And if we rely on the reality of voting, which is limited to interruption of breath on the exhale, when exhalation is considered "continuity", and voting is "interruption of continuity", then we can rule the whole audible expression of the throat.

Voice rbythm: this is the goal of synchronizing the movements of the tongue and the opening of the throat in language expressions. This is the accuracy of synchronization between the opening of the throat and the valve in the process of absolute voting, that is, both, with language and without language. This rhythm remains for the elite of receptors, speakers, singers and professional actors, whether it is in studying or practicing, and it is rare for non-singers or with experience associated with great talent or overt talent (Génie phénomènale). And this phenomenal talent as important component of speed technology is the one and only criterion for separation when discussing the aesthetics of audiovisual performances.

Therefore, if this element is violated, the full projection of the work from the audible of art is failed, whether it is linguistic reading, reading, intonation or phonemic, linguistic, representative expression.

Vocal sense (sensitivity): this is a close connection between the feelings of a person and his voice. In other words, it is a subconscious expression of sound. And we really know that people are similar in phonemic elements, such as fear, joy, anger, sadness, etc. ... except that they do not correspond to each other in this. The reason for this is clear: It is a feature of the independent "I" (Ego), on the one hand, and sensual vocal talent, on the other. Thus, it is a state of sound that requires study, testing and activation, translating it from the subconscious into intention and conscious will. This is what the actor, apparently, needs most of all in order to normalize the personality of others in his acting performance of the role he plays.

Vocal Timbre: we mention that it is one of the colors of voice expression and it is fixed and cannot be changed or varied, because this is the first and main nature of a person that distinguishes him from others, and, as we have already indicated, they are fingerprints due to the fact that they distinguish one person from another person, and therefore they are a phonetic fingerprint of a human individual that we call "Voiceprint".

Thus, the professionalism of the voice is to control the sound and its methods, as well as improve it in accordance with technical, applied and academic standards. 
And these standards deal with a relatively limited area, according to the difference in time, place and level of civilization of the society in which they exist.

And since singing and musical notation are an introduction to the study of the voice and its professionalism, the aspect that is the color of its cultural and traditional ways prevails in its study. This seems more effective than learning and practicing phonemic performance only. Therefore, a person can professionalize singing in common colors between East and West, losing features between them or giving priority to the influence of his civilization on the act of the second. Thus, we can say that vocal professionalism requires a comprehensive and in-depth study of its origin in the east and west, and, in our opinion, it involves several vocal specializations at the level of university degrees and, for example, we mention:

- East singing,

- East Arabic language performance,

- Opera singing,

- Romantic singing,

- Eastern vocal performance (including Eastern singing, rhetoric, poetry, fairy tales and theater),

- Western vocal performance (including literature and expression),

- Voice gesture (expressive voice without words).

We cannot, as is the case, unless we get to know the most important skills of vocal expression, while paying attention to the big difference between singing on the one hand and the other vocals mentioned on the other. And this is that singing strives for consistent phoneme accounts with a certain time value for this, while other arts do not adhere to this, but rather do it instinctively and moodily with the performer. And these vocal skills are:

- Public Speech "Oratorio",

- $\quad$ Singing,

- Diction,

- Tajwid "mastering full reading before singing,

- Executive or acting voice.

\section{Oratory or public voice performance}

It is the art of dealing with people with the goal of attracting, persuading and endorsing the idea. In it, all expressions of the vocal language converge for this purpose. And rhetoric is initially a literary art that relies on spoken words in 
communication between the preacher and other people. Considering that public discourse was embedded in culture and science during periods of civilized prosperity among Greeks and Arabs and practiced by rulers, princes and people of thought, and then characterized by the quality of language and grammar. While rhetoric actually seems to need a large vocabulary, strong sense and good descriptions, rather than linguistic, verbal or phonemic knowledge. This is enough with an innate expressive sound movement, and there is no need for knowledge of phonemes. And the most important elements of public speaking are:

- Absolute phoneme or free voice degree,

- Changing vocal strength,

- Speed of language and sound,

- Sense of subject,

- Excellent audio version,

- Active diaphragm movement.

And with this content, rhetoric looks like it is close to integrated lyrical art because of its inclusiveness, such as singing on common elements between them, without differences in language, since singing can take place without words, but rhetoric does not work without words that seem to her priority.

\section{Singing}

This is a sound presentation designed to complain about joy and express feelings for all people or some of them. And with a complete commitment to satisfy the phoneme degree and organize its sequence to serve the complaint or the resulting sensual expression.

In this context, we quote the words of the philosopher and writer Gibran Khalil Gibran from the chapter on music, where he says: "I sat near those whom my soul loved, I hear her talk. I sailed in space without limits, where I see the universe as a dream, and the body as a narrow prison". We personally composed the musical work and the melodies of these eternal phrases in the work entitled "Cantata of Music" "Lyric of Music".

Regarding several definitions, we note a correlation or coincidence between the reading and singing technique, and in fact this is due to the lack of thorough and indepth studies to confirm the gaps and differences between the two abovementioned arts.

Elements of singing:

- $\quad$ Organized Phoneme Degree, 
- Changing Vocal Strength,

- Speed or rhythm,

- Feeling,

- Beautiful timbre,

- Good audio version of voice,

- $\quad$ Movement aperture (Diaphragm).

Singing also differs from rhetoric in that it does not appeal to people, but is limited to personal expression, and then the recipient listens to it and aesthetically accepts or rejects it, while rhetoric does not occur without referring to others with full intention and determination. The irrefutable evidence is that the singer sings alone, and the sermon does not perform the sermon in isolation from others.

As for the types of singing, we say that there are many of them, but they are reduced to three for us as follows:

- International Opera Singing,

- Eastern singing,

- Free and modern expressive singing,

- European singing.

International opera singing. This is the highest professional singing in international phonetic expression, and its birth is associated with the revival of civilization in Europe in the seventeenth century. Where all art flourished, including music and lyrical art.

Eastern singing. By its nature, it differs from opera singing to the point of contradiction with it, since it divides it into several elements, we note the most important of them:

- Vocal projection,

- Type of voice,

- Voice feeling,

- General vocal expression,

- Vocal Strength Changes.

Free and modern expressive singing: lyrical art that emerged from the art of opera singing and popular and civil singing in Europe. Similarly, in the Arab East, besides the fact that it comes from Quranic singing, folk and civil singing, it seems to be influenced by European and other singing art, especially after the fall of Baghdad by the Mongols in 1258.

Modern singing and its basic elements: 
- Free Melody,

- Free performance,

- Quoting Professional Singing,

- Relative result in aesthetics,

- $\quad$ Ease and complacency.

- Avoiding the limitations of serious opera or oriental singing

And all these differences between the art of Arabic and Western singing make us distinguish them with a noticeable difference in the most important elements of the performance of the art of singing as a whole in the following table:

Table 2. Comparative table between the components of Western and Eastern Singing

\begin{tabular}{|c|c|c|c|c|c|c|c|}
\hline & \multicolumn{6}{|c|}{ Elements of aesthetics between western and eastern } & \multicolumn{2}{c|}{$\begin{array}{c}\text { Singing } \\
\text { singing }\end{array}$} \\
\hline $\begin{array}{c}\text { Full } \\
\text { Aesthetic }\end{array}$ & $\begin{array}{c}\text { Melodic } \\
\text { Notation }\end{array}$ & $\begin{array}{c}\text { Prior } \\
\text { Aesthetic }\end{array}$ & $\begin{array}{c}\text { Accuracy } \\
\text { In } \\
\text { performance }\end{array}$ & Improvisation & $\begin{array}{c}\text { Full } \\
\text { Notation }\end{array}$ & $\begin{array}{c}1 \backslash 4 \\
\text { Ton }\end{array}$ & \\
\hline no & yes & yes & yes & no & yes & no & Opéra \\
\hline yes & yes & no & no & yes & no & yes & Eastern \\
\hline
\end{tabular}

\section{Categories of singing}

After we have explained about the aesthetics of singing in the West and in the East, we must present a classification that distinguishes types of singing absolutely and equally, both in the East and in the West. After the above-mentioned paradoxes between eastern and western singing, we confirm that singing is a global aesthetic that does not stop either in the East or in the West, but goes beyond them to the rank of all mankind, where its basic characteristics seem unified and understandable to all nations and peoples. Accordingly, we classify singing types as follows:

1) Simple singing,

2) Professional singing,

3) Full singing.

Simple singing: this is singing that expresses complete sincerity in the soul with the least possible number of phonemes and melodies. So, what are the elements of simple singing? ... And the answer is that we conclude from the analysis of singing in its simplest form, even the most complex. And we include elements of simple singing as follows:

1) Correct Melody,

2) Truthful Sense, 
3) Plain vocal timber,

4) Rhythmic and simple performance Inborn expression,

5) Inborn expression,

6) Simple song,

7) Little lyrical experience,

8) Adopted simple language (unperfect),

9) Lack of diversification of vocal dynamics,

10) Lack of experience in language diction.

Professional singing: this is what singing does with minimal aesthetics. This is in the general and relative concept of the society that it contains the singer. So, professionals earn a living by singing. And this seems to be the main craft for them, so that it allows them to provide what others cannot offer from mastery in this art and its representations, which makes others happy.

The word "professional" means having an outstanding technical craft that few of them satisfy the needs of many people. It also requires professionalism in its owner to practice a profession related to this art, and thus profit from it as a primary resource for his livelihood. Thus, we have a visualization of the components of professional singing as follows:

1) True and excellent tonalism,

2) Truthful sense,

3) Distinctive voice timber,

4) Complete rhythmic performance,

5) Thoughtful expression,

6) Lyric works of all levels of composition,

7) Great lyric experience,

8) Financial reward for the performance,

9) Core profession,

10) Average diversification of vocal dynamics,

11) Experience of language speech and diction,

12) Good language.

Full singing: this is the most integrated type in lyrical terms, so it does not adhere to conditions that limit the breadth of his aesthetic areas. This is a song that arises as a result of the creative self-perception of the composer and singer together, not opposing the fans and asking his connoisseurs. This is because the artist goes beyond the taste of the audience in order to first of all achieve his satisfaction.

These specifications for full singing apply to specifications for full musical art, especially its symphony. We give an example in this regard when Ludwig Van 
Beethoven presented his nine symphonies in a row, as an elite music audience rejected it at first sight. Nevertheless, he was subjected to a new aesthetic through the repeated recognition of taste, thanks to extensive publications and appearances. After that, he became the aforementioned artist without contests and competitors, discussing his artistic rationale.

And here we do not depart from emphasizing the lyrical aesthetics of every creative person, both professional and unprofessional. And therefore, we do not know the sources of the new aesthetics, except through experience, hearing, and the search for the seriousness of one or another creator. This is because people do not know where aesthetics are when they follow it after it is discovered. Thus, full singing is an art that does not know the boundaries of the familiar from what preceded it to people, but rather presents itself again for discussion and decision-making. And most importantly, this is after the creative design of the original artist.

Full singing consists of the following elements:

1) True and excellent vocal tonality,

2) Truthful sense,

3) Distinctive vocal timber,

4) Complete rhythmic performance,

5) Thoughtful expression,

6) Lyric works of all levels of composition,

7) Great lyric experience,

8) Creative innovations in melody and rhythm,

9) No technical limitations,

10) Absolute Subjectivity,

11) Great phonetic experience,

12) Great language,

13) Vocal coloring dynamic,

14) Core profession or secondary hobby,

15) Financial rewards or not,

16) Voice readiness or intensity (its speed) or Velocity.

Thus, the comparison is carried out according to the following table:

Table 3. Comparative table between three types of singing

\begin{tabular}{|c|c|c|c|}
\hline \multicolumn{4}{|c|}{ Types of Singing } \\
\hline (Components) & Simple & Professional & Perfect \\
\hline Ton & Good & Excellent & Excellent \\
\hline Sense & Unstable & Good & Excellent \\
\hline Timber & Not Important & Excellent & Excellent \\
\hline
\end{tabular}




\begin{tabular}{|c|c|c|c|}
\hline Rhythm & Good & Excellent & Excellent \\
\hline Expression & Weak & Good & Excellent \\
\hline Creativity & Simple & Big & developed \\
\hline Experience & Small & Big & Big \\
\hline Wage & Unstable & Excellent & Big or None \\
\hline Profession & Not Basic & Basic & Basic or None \\
\hline Dynamic & No & Good & Excellent \\
\hline Diction & Unstable & Excellent & Excellent \\
\hline Update & No & Limited & Big \\
\hline Reading & Unstable & Good & Excellent \\
\hline Property & None or Small & Limited & Big \\
\hline Voice readiness & Not Important & Unstable & Entrust \\
\hline
\end{tabular}

Thus, we have identified priorities in the importance of determining lyrical art(singing), which are valuable material for social structure in the scientific research of this art. In addition to setting tasks in the field of art and their implementation, they may in the future become subjects of scientific theses that will greatly benefit scientists, art and thought, literature and others.

\section{Diction (speech of expression)}

This is the art of reading linguistic texts with the full phonetic expression of what they mean, people and sensations. And this is with all the variables and constants in its technique, so that the resonant or melodic path, strength, quality and sensitivity change. It is aimed at improving the aesthetics of language and speech in the performance of the described story, idea or situation in order to bring them closer to the feelings and perceptions of the audience.

These definitions and explanations are broad and correct, with the exception of some, especially in a song or poem when it sings, because singing replaces speech. And if there had not been this difference between the technique of speech and singing, singing would not have its own definition, as well as speech. And here we want to confirm that speech contains singing and not the opposite, that is, singing can occur without a verbal language, on the one hand, and the singer may not master the language, on the other hand. Thus, our opinion is an art based on two independent art forms:

1) Excellent linguistic intonation or pronunciation,

2) The art of phonetic expression, which we discuss in this article, including singing

The most important elements of speech are the following:

- Vocal degree,

- Changing Vocal Dynamic, 
- Speed or "Tempo",

- Feeling,

- Vocal Timber,

- Good language,

- Professional Voice,

- Good pronunciation,

- Voice Attack (voice start),

- Lyric diaphragm movement,

- Tune,

- Voice Readiness or Intensity (Velocity).

Clarification of linguistic meaning occurs through the art of speech, which is based on the study of the human voice in its tonal degrees and on its musical study. This allows the student to control voice tonality according to the values so that they look clear, which indicates the effect on the ears of the listeners. In addition, consensus falls on the coincidence of music, as part of an organized piece of audio, and the art of broad vocal expression, which contains music and singing along with speech, rhetoric and simulation.

The real equation between diction and its components is as follows:

Diction $=$ full voice and technique + excellent language

And a voice with full technique is the voice to which we devote all this research, and it must be unique and distinguished. Later we will provide detailed equations for each of the vocal arts included in this study, with clear graphic comparisons to facilitate the study of voice, its methods, and expressive capabilities. We also strive to bring it closer to singing, which became aware of its writing or notation (musical notes), its manners, applications and international professional performances.

\section{Intonation (Improvement of language) "Tajwid"}

This is the science and application of linguistic phonetics and mastery of letter exits, and, as we will see, includes some of the basic elements of the human voice. And the meaning of "Tajwid" [1] in the language is the act to decorate and improve, just as it means in the Holy Quran the improvement of the language and verses of the Koran, repeating them. And intonation does not mean phonemes in the meaning of melody, but it consists as the art of linguistic performance of the following elements:

1) Vocal projection under word segmentation,

2) Mastery of the movement of the tongue, 
3) Phonetic letter-related techniques,

4) Verbal movement of the veil or diaphragm,

5) Voice readiness or intensity (velocity).

And "Tajwid" (pronunciation improvement) or intonation is closely connected with the art of expressive public voice, including singing traditional, classical and international, especially from the point of view of the source of the voice of the larynx. And this association confirms itself when a singer in a bad language distorts the art of sound and singing and, accordingly, all vocal arts. Nevertheless, from the point of view of the aesthetics of the material and the melodic performance, its performance will be interrupted if it misuses the intonation and the letters come out. This is the reality of concept that modern singing may not require a different language and excellent intonation. The "Tajwid" element that distinguished it from the rest of the vocal arts is "Word Segmentation" which differs from the other vocal arts of expression. Here we confirm the uniqueness of Tajwid by word segmentation, in contrast to singing, which is closely related to the combination of smoothly segments or "syllables" of words in contradiction to their segmentation in the art of tajwid. For example, in news reading, word segmentation prevails when the merging and joining of words dominates strongly in singing.

Most listeners can confuse voice and melody on the one hand, and language, and its intonation on the other. This is due to the reason for poor performance of the voice or melody, while the real reason lies in the outputs of letters and linguistic correctness. On the contrary, it can be confused with this, and they explain the causes of distortion and tajwid letters, while melodic singing is the cause of this. It should also be noted that the most important component of voice is the "voice timbre", that is, the acoustic tissue that underlies the formation of any human voice. Therefore, we will not list it in the comparison list.

After this detailed explanation of the performative forms of the human voice, it is necessary to present a visual comparison that proves the coincidence and participation in the composition between them, especially between singing and other vocal arts. Moreover, for several centuries singing was distinguished by the science of music. While speech, rhetoric and tajwid did not yet have the science governing it. All this confirms the purpose of this study, which is mainly aimed at raising the level of non-lyrical performances to the level of lyrical ones. Thus, phonetic expression advances in achieving a complete system of knowledge and voice in the Speech, and not just in terms of singing music. And we will list a comparison of the elements common to all types of voice performance and its art. It looks like this [2]: 
Table 4. Common components of vocal arts

\begin{tabular}{|c|c|c|c|c|c|c|}
\hline \multirow[t]{2}{*}{ Tajwid } & \multirow[t]{2}{*}{ Diction } & \multicolumn{3}{|c|}{ Singing Types } & \multirow[t]{2}{*}{ Oratory } & \multirow[t]{2}{*}{ Technics } \\
\hline & & Simple & Professional & Perfect & & \\
\hline No & Yes & Yes & Yes & Yes & Yes & Ton \\
\hline No & Yes & Yes & Yes & Yes & Yes & Dynamic \\
\hline No & Yes & Yes & Yes & Yes & Yes & Tempo \\
\hline No & Yes & Yes & Yes & Yes & Yes & Sense \\
\hline $\mathrm{No}$ & Yes & No & No & Yes & No & Timber \\
\hline Yes & Yes & $\mathrm{No}$ & $\mathrm{No}$ & Yes & $\mathrm{No}$ & Language \\
\hline No & Yes & No & Yes & Yes & No & Experience \\
\hline Yes & Yes & No & $\mathrm{No}$ & Yes & No & Spell \\
\hline Segmentation & $\begin{array}{c}\text { Sing } \\
\text { Segmentation }\end{array}$ & Singing & $\begin{array}{c}\text { Sing } \\
\text { Segmentation }\end{array}$ & $\begin{array}{c}\text { Sing } \\
\text { Segmentation }\end{array}$ & Segmentation & Diaphragm \\
\hline No & Yes & Yes & Yes & Yes & No & Melody \\
\hline Yes & Yes & No & Yes & Yes & Yes & Attack \\
\hline Yes & Yes & No & $\mathrm{No}$ & Yes & No & Readiness \\
\hline
\end{tabular}

The word "yes" means that the technology shown (singing, rhetoric ...) contains the corresponding element (degree, power ...), and the word "no" means its absence. Accordingly, we see that the basic common elements are one of the three most popular forms of art, such as singing, rhetoric, and reading (Tajwid). With the exception of tajwid, which, in particular, means linguistic performance and is devoid of human sensitivity, which makes it more a science and technology than art.

Thus, the image of vocal professionalism is clear, and it was limited to the three main types of vocal arts "Diction, Rhetoric, and Singing," and the fourth "Tajwid" (not correctly called "intonation") seems to be an important element, and each is the fifth and most important vocal art, and we are devoted to this study, and this is representative vocal art, that is, a common expressive voice that contains the four arts mentioned above, this is an "actor or theatrical-dramatic voice".

\section{Segmentation and splicing of the human voice expressions}

The human voice is a brilliant genius instrument, capable of realizing everything that enters into human thoughts and feelings through voting and has complex cases, and possibly only complicated, science and technology cannot fully control it until today, but we confirm that the results of this study and our experience for almost half a century prove that the kinematic composition of the human voice is based on two types:

1) Splicing voice projection or long sound,

2) Segmented voice or short sound. 
And there is a long voice with its movement to the longest of them with the end of pulmonary respiration for each voice in its difference between one person and another, and there is a short voice from the shortest parts to simple parts that adhere to the ability of certain people.

And based on what was mentioned above, it is necessary to classify the vocal arts between these two elements of the vocal movement between the Segmentation and splicing (cutoff and the tide), knowing that the explanation mentioned in this research applies to these arts, but we want to emphasize the clarity of this aspect in the interests of knowledge and facilitate learning to play the human voice. In all his artistic and expressive abilities, we have included this schedule:

Table 5. Segmentation and splicing technique between vocal performances

\begin{tabular}{|c|c|c|}
\hline Mixing Art & Segmentation Art & Splicing Art \\
\hline Diction & News Reading & Romantic Singing \\
\hline Expression & Schooling Reading & Arab Tarab Singing \\
\hline Story & Explanation Reading & Flirty poetry \\
\hline Theatre Art & Voice Over Commentary & Spiritual singing \\
\hline Imitation & Critic Singing & Singing to children \\
\hline Theatre Singing & Scientific Reading & \\
\hline Opera Singing & & \\
\hline
\end{tabular}

Thus, the cut and tide (Segmentation and Splicing) are the two only movements of the human voice and all sound objects. The human voice is distinguished by the aesthetic beauty of the tide, while the cut in it enhances the rhythmic aesthetics, and with these two movements all kinds of general vocals and expressive art are obtained.

\section{Actor or drama voice}

The human voice is the most clever and complex instrument, except that it gives a person acts of greatness and perfection, and a representative (acting) voice is an apparatus capable of performing all vocal arts, in addition to linguistic expression, from fiction - narration to reading news and general narration, with all the attendant influences like screaming, laughing, crying, nagging, moaning and so on. In other words, a representative voice is one whose owner can imitate the characteristics of dialects and individuals of different nationalities. And according to what the German scientist - Orientalist Kurt Bruffer confirmed, thanks to his knowledge and experience. A German scholar who studies Arabic well also confirms that dramatic art was rooted in the art of gramophone and imitation.

An actor can play the role of a singer, orator or others, a religious and its opposite, or a bad and opposite character, etc. Where all these pushes those who 
profess to be a broad-based art, practice every role of the above characters, while their normalization will not be achieved with all its expressive potential. Such as facial expressions and accompanying techniques, body movements and dances, as well as the flexibility of voice, including singing, speaking, diction and other vocal arts.

And the Arabs' theater did not take the form that we knew later, but with its basic elements, detailed and embodying the best embodiment. In the Arabic novel, history, eloquence of news, hadith (conversation) and other arts of the human voice, such as rhetoric and poetry. Whereas listeners who were opponents and allies needed those who spoke at the highest level of rhetoric.

And the great Arab-Islamic civilization cannot be deprived of theatrical art and one of its most important elements, except that it is deprived, perhaps, of the name and definition of the time and place of theatrical performances, which means that the theater originated in Europe from anecdotal, fictional and representative expressive data, voice and movement in the midst of Arab civilization. In addition, talk of Arab theater was not mentioned in history until the middle of the nineteenth century AD.

A professional actor has talents and skills, talents that are born with him, and skills that he acquires in lessons and in practice. You can also download talents, and not develop them, an experience that develops in performance, especially in vocal performance. And the voice for the acting profession is the largest part of professionalism, and without exaggeration, we can say that the amount of this is almost $70 \%$. And the reasons for this are connected with the historical and hereditary role that he played and still plays with the voice of the larynx in the life of man and his civilizations. From expressing surprise and fear to explaining joy, delight and satisfaction through vocal forms, which, thanks to their influential actions, have become the media language and the term of understanding between people in the same group and between groups that have passed through the stage of peace and earth.

And media, as a standard known to people, is much more active and develops through audio than through visual. Since the dawn of human existence on earth, people have exchanged supposed voices, that is, known voices, at every meeting or accident occurring, even before a person reaches the languages that we know today. As for the stage use, it was developed in parallel with the phonemic use, but with a rate that does not exceed $30 \%$ of the expressive exchange between people and, possibly, much less.

From the very beginning of the development of media art, linguistic and nonlinguistic, the facts of expression and communicative use among people emphasized 
the superiority of speech, singing, oratory and the exchange of conversations between gestures and signs between people. The most convincing evidence of the superiority of phonemic expression over the silent expression of gestures is the recent creation of sign language and nodding deaf-mute, i.e., at the beginning of the twentieth century. While languages and vocal expressions between people appeared at the dawn of a well-known and written history, at least about 6000 years ago and much earlier, historical evidence and archaeological excavations at the strongholds and ruins of the earliest civilizations, especially Mesopotamia, the banks of the Nile, China, point to India and others. Not to mention the new civilizational development in Europe, from which it grew on the basis of the ancient East, and which confirmed the superiority of the audible meaning over the visible, which are two ways of expression between people.

Based on the foregoing, we believe that the actor's specialization in vocal expression is an essential necessity to achieve his career after graduation. For this, it is necessary to spend at least 800 hours over two years studying and applying the voice, its exercises and general expressive techniques, including singing.

Based on the above comparison between the general and common elements of the art of the human voice, we must develop a science and application for the study of the human voice and its technical and practical applications. This is what we list later in the context of this extensive study. Moreover, this study consists of two main parts, one of which is theoretical, through which we are now passing, and the second is some applications.

\section{Acting voice between discipline and improvisation}

An acting (representative) voice is more evident in learning and acquisition than in nature and spontaneity. This is because the actor has studied various expressive types of phonemes and various dialects. And this is the way that preserves and normalizes what his teachers teach him or the voices who want to remember and perform it. However, the voice of this actor remains confused between discipline and improvisation due to the lack of control over modern audio technologies.

As for those who demonstrate a more ready-made vocal talent, they use excellent vocal expression in terms of performance, but it is limited in terms of development and coloring.

From what was reported, it is clear that the actors are currently of two different types. One of them has good vocal quality and some oral initiation, and the second one does not have good vocal quality, and indoctrination is useless. And others make up the largest share of the total. Thus, the problem of phonemes presents itself, 
arguing that the professionalism of voice without scientific and analytical methods remains limited and generally inadequate.

A disciplined voice is, in our opinion, a voice that moves on the basis of talent and improvisation, on the one hand, and on the basis of scientific and technological achievements, on the other. With our definition, the percentage of talent and improvisation is that it does not exceed 10\% (ten percent), and the largest percentage remains for knowledge, practice and technical knowledge, and it is at least 90\% (ninety percent). Hence the importance of the inability of the association of knowledge and art to solve this problem through teaching at institutes and universities, since it guarantees the minimum level of success in the field of voice art, on the basis of which we devoted all this research.

Thus, a disciplined and excellent voice remains a voice that should be fully controlled by its owner under conditions no less than good talent and sufficient knowledge, accompanied by adequate applications. And with a minimum of no less than professionalism of techniques and performative types of voice, which we will see in more detail in our book "Th human voice - Genius instrument" issued in Beirut - Lebanon on the year 2000 and included in the work "The Encyclopedic book on music and audio art in Lebanon and worldwide" issued on the year 2016 in 680 pages. Before that, we must emphasize the importance of the Voice of the Buzz (Voix klaxonnante), which is launched in partnership between the gill (nasal cavity) and the throat in which the larynx is located. It is this voice, confirmed by historical and civilization tests and testimonies, that allows the performer to maximize the expiratory economy and restraint that regulates linguistic sounds.

Therefore, we believe that it is necessary to teach the actor the following topics before practicing with the voice or performing exercises related to the human voice:

- Voice Machine and anatomy of the larynx (Anatomy - Physiology),

- Voice structure (voice elements),

- Vocal taste (types of voice and aesthetics of performance),

- Absolute phoneme and phonemic gamma, including singing and its types,

- Attacking voice (Start), including mastering the process of pelvic breathing,

- Vocal Exercise,

- Study of Vocal and Audio Technical Lesson,

- Artistic voice art composition,

- Vocal audio project, fullness of expression in the subject of the full story. 


\section{Vocal device}

Its most important mechanical components are:

- Lungs,

- Tracheostomy,

- Vocal tendons in the larynx (Two vocal strings),

- Tongue, inner cheeks and nasal cavities.

The voice structure and its most important non-mechanical parts:

- Timbre,

- Degree or melodic tone,

- Vocal dynamic,

- Vocal start,

- Speed,

- Sense of voice,

- Vocal rhythm,

- Linguistics and Languages,

- Acoustic Density.

Vocalization taste consists of:

- Voice Type (Dry, Brilliant and Buzz Voice),

- Vocal and aesthetic performance,

- Character and timbre of voice,

- Phonetic-linguistic synchronism,

- Synchronization of respiratory productive practices,

- Beautiful performance, general singing or expression,

- $\quad$ Pure vocal performance (no language),

- $\quad$ Linguistic phonemic performance (phonemes, vowels and consonants).

Absolute phonemics scale: the most important elements:

1) The difference in the phonetic movement between the steps up and down without mixing up and down;

2) Know the lowest bass of self-voice, whispering to the closest listener;

3) Know the sharpest and loudest voice whispering to a distant;

4) Practice and testing according to one degree;

5) Practice hearing and throat repetition;

6) Know how to make a voice of a certain degree before you hear it, that is, practice using sound memory; 
7) Practice silence time after listening to write to the brain.

The musical scale of voice: its most important elements:

1. Hear and repeat the degree yourself,

2. Detection of the lowest degree in the subjective voice. Whisper to the closest listener,

3. Detection of the highest pitch in the subjective voice. Whispers to the distant,

4. Octave (1st and 8 th degrees of the musical scale),

5. Staircase (from 8 degrees) in natural major tone,

6. Scale (from 8 degrees) in a melodic major tone,

7. scale (from 8 degrees) in a harmonic major tone,

8. Repeat the scale, leaving its frames, up and down, in accordance with the field for your own voice,

9. Ancient Greek tonal scales with seven tones.

Voice production and its most important parts:

1. Practice the movement of the air valve, i.e., the annular opening of the throat,

2. Learn the letters, $(\mathrm{A}),(\mathrm{O}),(\mathrm{Y}),(\mathrm{E}),(\mathrm{I}),(\mathrm{R}-$ French) or ( $\dot{\varepsilon}$ - Arabic) and (ON and $\mathrm{Ma})$, (Unnnn ... and Mmmmm ...) accordingly with one exhalation,

3. Staccato or Phoneme Segmentation,

4. Capture air in the full lungs and remove it with full control. Without voice and then with voice,

5. Expansion of breath with maximum strength (fortissimo), making the longest sound,

6. Expansion of breath with the weakest force (pianissimo), making the longest sound,

7. Extension of the longest breath without sound.

\section{Singing and non-singing voice}

A non-singing sound includes speech, rhetoric, diction, narration, news and all kinds of phenomena of prose and phoneme in a person's life, with the exception of singing, whether or not rhythmic. And precisely, that is, a non-singing voice, and, therefore, the largest part of the human voice, which requires research and testing to put it in the framework of discipline and control in a person, as happened today with singing.

In terms of specificity, a non-singing voice can be described as voice free from a controlled melody and balanced rhythm. This is the most important advantage in the difference between singing and non-singing voices. And if a non-singing voice is devoid of a disciplined melody, it is filled with a melodic uncontrolled movement [4]. 
It also seems to be a rich rhythmic beginning and therefore is the main source of a disciplined melody, that is, a musical melody, in terms of tonal context, on the one hand, and rhythmic content, on the other. And the linguistic voice is the mother of the lyrics. That is, the lyrical sound comes after a common expressive voice, because it comes from it and is divided into a regulatory framework. This is the basis of music science with all its written and practical applications. This is because the lyrical sound is a metaphor for changing the number of vocal-limited numbers (i.e., melodies) in addition to the repeating kinetic segment (i.e., rhythm). Here we must define what "melody" and "rhythm" are.

Melody: this is a change in phoneme levels from two or more degrees (degree) to what constitutes a group of sounds called a melody if they are performed sequentially in turn, and becomes a work of art if repeated as a group, and becomes a musical composition, if to it other groups are added, forming one subject with it.

And in the Noble Quran, we read in the Surat Muhammad in verse 30 ".... and let them know them in the melody of the saying", where people mean their people, their tribes and different dynasties. This confirms the meaning of the composition in a speech, since it indicates different dialects between peoples from one region to another, from one city to another and from one country to another ...

Then the meaning of this word "melody" developed so that it describes those who compose music and songs. This means that this is an excellent quality for those who change the standard language and violate its laws in order to aesthetically expand the word, so that the temporary phoneme of linguistic syllables and phonetic symbols can be manipulated with a deviation from what standard language laws allow. And here this word carried all modifications of the linguistic melody of music in order to do what is called a song, poem, mawal or other forms of singing.

Rhythm: This is an equal and balanced repetition of a syllabic sectional assembly consisting of at least two focal points. For example, we say and repeat more than once:
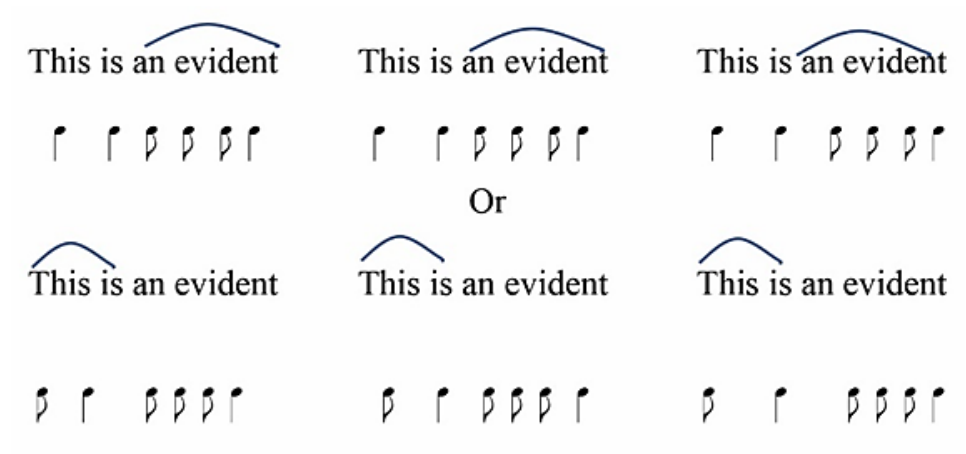


\section{This is the struture segmentation of the languge words in their innate}

form with their rhythmic repetition

The pronunciation of these words leads to a beaten rhythmic sound on all sounding objects or musical instruments, from the human voice to percussion and musical instruments in general. And in this way, he can justify the accompaniment of poets and poetry receivers in the "Okaz market" of Jahiliya (Before Islamic period in the Arab Peninsula) with percussion and rhythmic instruments, especially a rod which strikes a drum or any sound object to enhance the tone of speech and its effect on listeners. In the above example, there is no codification of signs (stress) indicating the location of gravity or verbal pressure (Syncope, Accent).

With regard to the aforementioned counterpressure movement, which is called "Syncope", we can confirm that it is the rhythmic movement resulting from the reaction against an action. And this opposite movement falls on the second part of the musical beat and not on the first of it, since the first beating in any musical rhythm is for the action and not for the reaction. Thus, we make it clear that "action" and "reaction" are in the constant interaction between humans, especially in cases of disagreement and conflict between them.

\section{Beating the opposite rhythm of the natural rhythm which is called}

\section{"Syncope"}

All the rhythmic forms of musical meter are divided into two types: strong and weak (Fort et Faible), (Strong and Weak). The first beat of the musical text is the strong, and in contrast, in certain cases, it may be the opposite, where the strong beat replaces the weak, and vice versa, the weak replace the strong, where the dramatic emotional expressions in the human being during sudden emotion solve the problem of natural movement, so it seems unnatural or rather identical to the state of stability prevailing in human life, so the rhythmic musical text comes expressing this, and writes the "Syncope" and is referred to by a free idiomatic sign like this $(>)$ or similar to it provided that it is explained, so the strong percussion pressure becomes implemented under the mentioned sign, and there are many cases of the "Syncope" which we have not mentioned here with the intention of generalizing but not limiting, and in general as follows: 

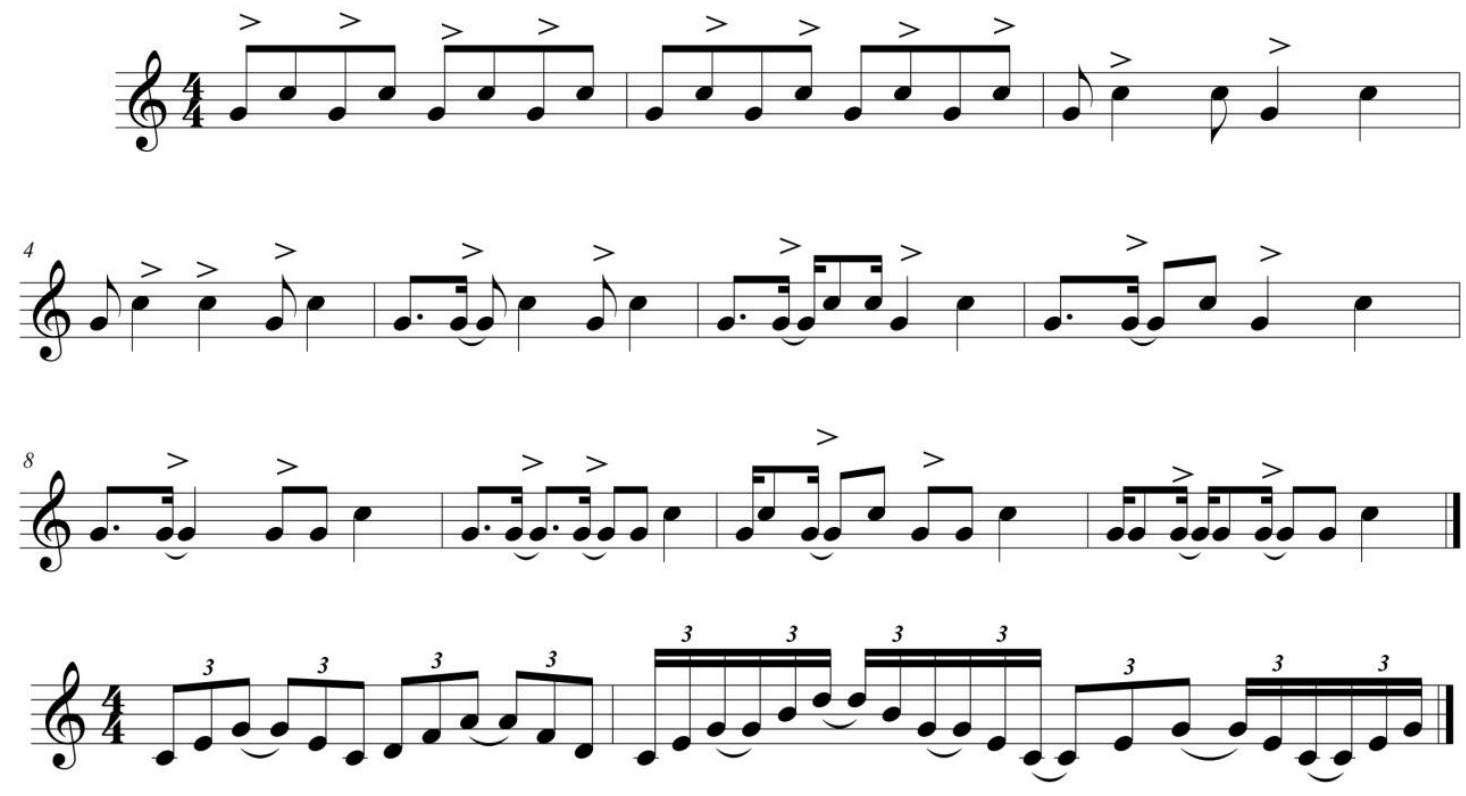

And here the importance of rhythm is emphasized in Arab and East Arab music, which mixed with the music of countries under the banner of the Islamic state in all its historical eras. We mention Persian, Turkish, Syrian and Egyptian in general. We confirm, according to historical facts, the great rhythmic richness of Arabic music taken from Arabic poetry, which was organized in the works of Khalil bin Ahmed and Al-Akhfash.

And we must mention the most important Arab and non-Arab rhythms, which are common in musical and lyrical performance in general. And we will start with the seniority of these types and rhythmic problems among Arabs and other people from ancient times to the present day. This shows the segmentation that we mentioned, which means rhythmic segmentation and does not depend on the type of vocal click in the rhythmic instrument, where it is necessary to distinguish between the two main clicks of the rhythmic sound: "Tak" (which is a sharp click) and "Dom" (which is a thick and bass click) by changing the direction of the vertical tail of the musical symbol [5].

Arab rhythms, like all international musical rhythms, consist of two main types: simple rhythms and complex rhythms. However, this means that Arab rhythms seem richer than the rhythms of any people in general. It is broader in terms of the integral part of the Arabic language.

Salim Saad was the first to confirm the "musical hearing" in every buman person in absolute, in denial of all theories and global concepts since the dawn of history, which used to say that there are people who do not enjoy musical hearing, and the solution has been developed by him through a special exercise that has become in Applying in institutes as a new subject, since the emergence of music schools and the 
profession of music education, teachers have relied on the musical hearing test to accept learners in music, so they reject the bulk of those who wish on the pretext that they did not enjoy musical hearing until the year 2000, and as a result of research and tests conducted by Salim Saad musical hearing talent has been proven as a blessing in human creation, but with the difference in the level of its appearance between one individual and another. (Encyclopedic Book on Music and Audio Art in Lebanon and the World - in 2016, including the book "The Human Voice is a Genius Instrument” (Beirut, 2000 p. 589)

\section{Musical hearing reformation}

When a person picks up the sound, he absorbs it completely with all of its mentioned elements. Some people are able to repeat the entire audible sound (according to an approximation), and some are few and rare to find, and some of them repeat the sound incompletely. And here in particular the problem of "musical hearing" arises, as it is necessary for us, before judging the performer, to analyze the aforementioned sound elements that he repeated and what he did not repeat. So that we determine the deficiency and the reasons for its occurrence and develop the necessary treatment to not fall back into the deficient performance.

There are those who repeat the audible voice incomplete in terms of vocal strength or emotional expression or in terms of vocal quality, so they do not receive widespread criticism. Whereas if one of the listeners repeats the audible sound with a decrease in terms of the musical pitch, the number of its vibrations, or its vocal position on the general scale, he faces an accusation that he does not enjoy musical hearing. The truth is, on the contrary, according to our opinion, he enjoys the inner and invisible musical hearing, which must be shown. This requires a person to practice and apply the process of what we called "hearing correction" to the degree of perfection, whereby he becomes able to repeat the audible without any defect in the musical pitch.

This defect is represented in the communication between the vocal memory and the larynx. And since the vocal memory needs some time to record and fix the audible and prepare it to direct it to the larynx ready with all its components, especially, its musical degree, the difference appears in the speed of communication between the vocal memory and the larynx. Some have good communication, while others have poor communication between vocal memory and the larynx. This was evident during our research and educational tests in the Acting Department, as 70\% (seventy percent) of the students had this problem called "musical hearing". So, we found ourselves compelled to deal with this matter, which has not yet been addressed until today, except by rejecting the owners of hidden hearing in the music institutes, as 
mentioned above, as everyone who suffers from this problem becomes refused and only a small part of them is accepted as they have ready musical hearing. Therefore, because the required and limited number of music students were satisfied, a large part of those who are refused are described as non-having musical hearing, and the remain without affiliation to musical institutes.

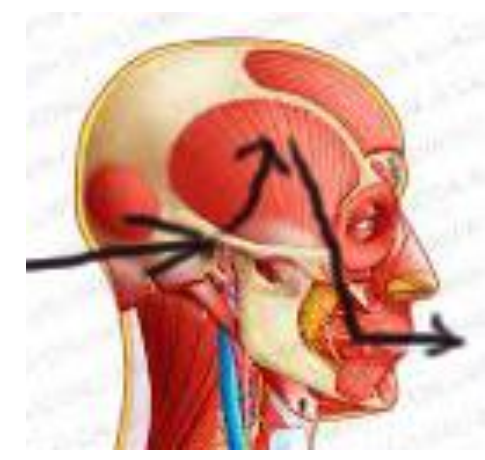

How was our first attempt to treat invisible musical hearing, that is, the first operation aimed at "hearing correction"? That was in the year 1992, after four years of our higher teaching and education at the university for vocal arts, which is not subject to curricula, references or firm research results. And after we were sure, through our personal experiences and research at the time, that the actor seemed to have an urgent need to memorize and repeat speech, singing, oratory and other arts of vocal performance, we set out to search for the cause and treatment of the phenomenon of what we called "apparent musical hearing" and "invisible musical hearing". Or "ready musical hearing" and "not ready musical hearing".

And after a large number of tests we conducted, we came up with a "hearing correction" for the first time in one of the students who did not enjoy musical hearing. And when we checked the reasons for success, and after repeating the first successful experiment, we found that the vocal memory varies with the speed of its performance from one person to another. What assured us of this are our vocal memory tests after an incident occurred, after watching a movie, or after listening to a musical or lyrical work. We asked each student individually about what he saw or heard, and the result was that most of the students fell short in the immediate description and only a few of them were good at describing it. In addition to the fact that most of those who enjoy apparent musical hearing fall short in descriptions. Which made us stand in front of a phenomenon that is difficult to understand and analyze, and we ask the following question: What is the importance of vocal memory for a musician who fails to describe and for someone who does not enjoy apparent musical hearing and improves the description? 
So, based on what we have mentioned, vocal memory appears mainly in the preservation of the voice and its repetition through the larynx with all the elements of the voice without any detraction. However, the communication between the memory and the larynx may be practiced by what suffices with some elements of the voice and not by all. Especially since the frequency of the sound in its musical degree essentially requires special attention and a special time, given what we have already mentioned that the need in vocal expression does not include the vocal musical degree in its priorities, but rather in its last ranks.

We have talked about the hierarchy of the elements of the voice according to time in the process of repetition between the vocal memory and the larynx. Based on the foregoing, we can define the problem of not possessing musical hearing and limit it to the time factor focused on mastering it. According to the excellent results of our tests in this regard, we give the following result for the process of acquiring or possessing musical hearing for those who do not have it by heredity: Producing the sound and creating a period of complete silence and quiet for a period that varies from one person to another. In general, it is not less than five seconds (5 seconds) so that the vocal memory can record and prepare the audible sound so that it is ready for repetition in the larynx. We summarize this process in three stages:

a) Producing and capturing sound by hearing,

b) A memory break in complete silence and calm,

c) The resonance of the voice in the student's larynx.

Exercises for the human voice on the scales of the quarter of the tone (of the degree), Salim Saad was the first to discover, apply and test it and devised a successful application approach in the new, complete global scale by adding the quarters of the voice to the twelve universal chromatic musical degrees in one octave that make the sound twenty-four starting points or musical degrees, after it was limited to twelve points in the current global exercises, so that the vocal exercises are conducted from 2 (two points) for each chromatic degree, where we use the keyboard converter to make whole the scale on a quarter of the tone instead of the half of it.

We apply the first exercise, e.g., from the lowest degree (A for example) on the normal degrees, and we apply the second exercise from the same degree converting all the scales of the keyboard to a quarter of a tone lower, and we apply the third exercise on the next in scale degree $\mathrm{b}$ flat(Si Bemol) canceling the conversion of all the keyboard degrees, we continue on the same degree converting all the degrees in a quarter of the tone lower, we continue on the degree B (Si normal) cancelling the conversion of all the keyboard degrees, we continue on the same degree B (Si normal) converting all the keyboard degrees to a quarter of the tone lower, etc.... So, we 
continue the exercise to the end with the highest degree of the trained voice. This way of training gives us the following degrees on 1 octave (24 degrees instead of 12):

1-A normal,

2-A converted,

3-b flat normal,

4-b flat converted,

5-B normal,

6-B converted,

7-C normal,

8-C converted,

9-C sharp normal,

10-C sharp converted,

11-D normal,

12-D converted,

13-D sharp normal,

14-D sharp converted,

15-E normal,

16-E converted,

17-F normal,

18-F converted,

19-F sharp normal,

20-F sharp converted,

21-G normal,

22-G converted,

23-G sharp normal,

24-G sharp converted.

The degrees in one octave are now 24 instead of 12 chromatic without the new 12 converted degrees discovered by us.

Below is an example of the musical noted degrees in the new exercise which we invented based on the quarter of the tone included in the new oriental keyboard.

Salim Saad exercises with quarters of the tone 

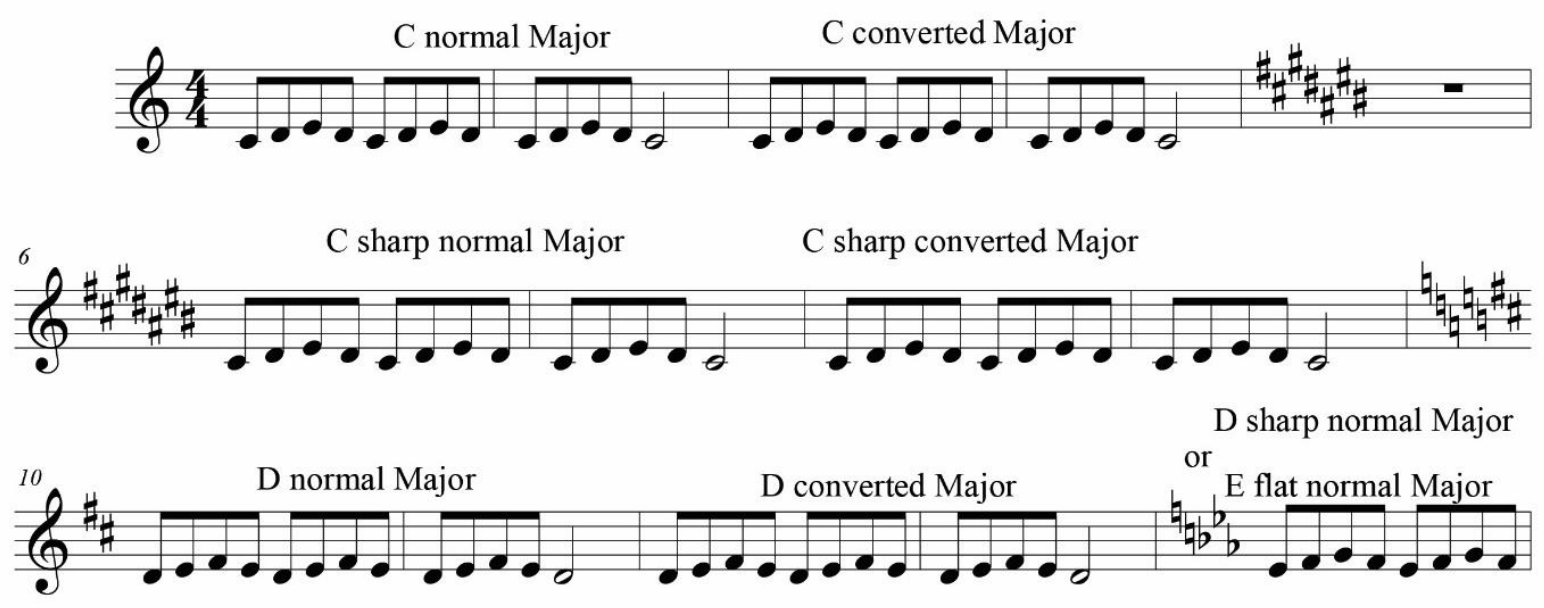

D sharp coverted Major
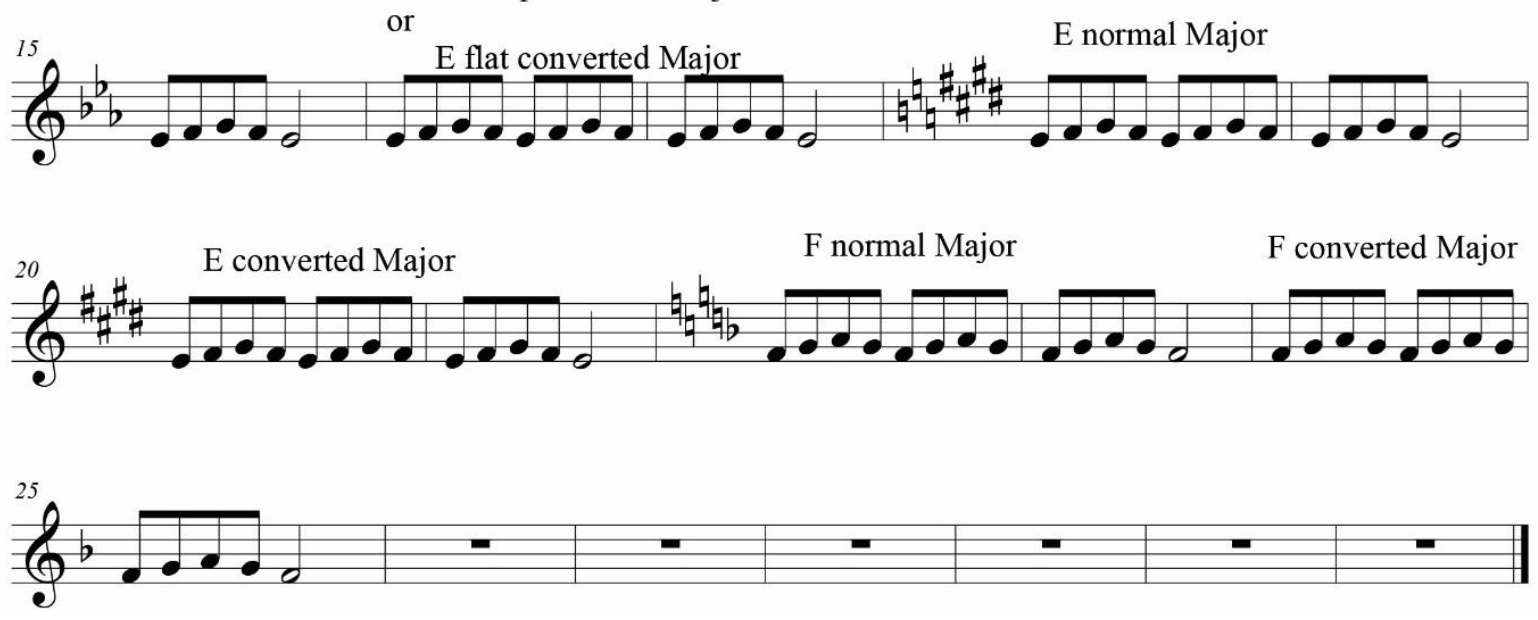

This means that we add a point of "Quarter Tone", which is "half of the half". And it was confirmed by Salim Saad through his tests, research and applications that the exercises of international operatic voices will reach a much higher quality in the application of their exercises on 24 points or more, depending on the enlargement of the voice register (it can be 29 chromatics which means 58 points with the quarters of the tone) and not only on twelve points in 1 octave, and this is on the basis of moving the human laryngeal tendon on 24 points and more as possible in 1 octave instead of 12 chromatic, this makes it more flexible and delicate, and the massage exercises, if they were limited to a few points, would not give good treatment results, like the continuous exercises of the points, that is, close together (Encyclopedic Book pg. 392 online or pg. 369 in paper).

15. Rehearsing the human voice on all pitches, including all quarters of the tone

One of the exercises of the human voice that gives great effectiveness in combing the larynx and its flexibility, which is applied today in most countries of the 
world, is the exercises of "Henrico Caruso". All exercises shall be applied in the "natural major" of the tonality of the any degree with its first three keys, and this exercise is conducted on all possible degrees for the owner of the rehearsed voice daily, which causes wideness and flexibility in the pitch of the voice and leads to raising the level of the quality of the vocal material to its maximum levels, provided that it is performed on each of The vowels " $a, o, i$, ou" etc. ... and more are from the universal laryngeal verbal-linguistic sounds, and therefore the voice of the trainee is gradually measured according to the number of chromatic or converted, semitones and quarters of the tone that he has become able to master, and we include this exercise in the international classical way:
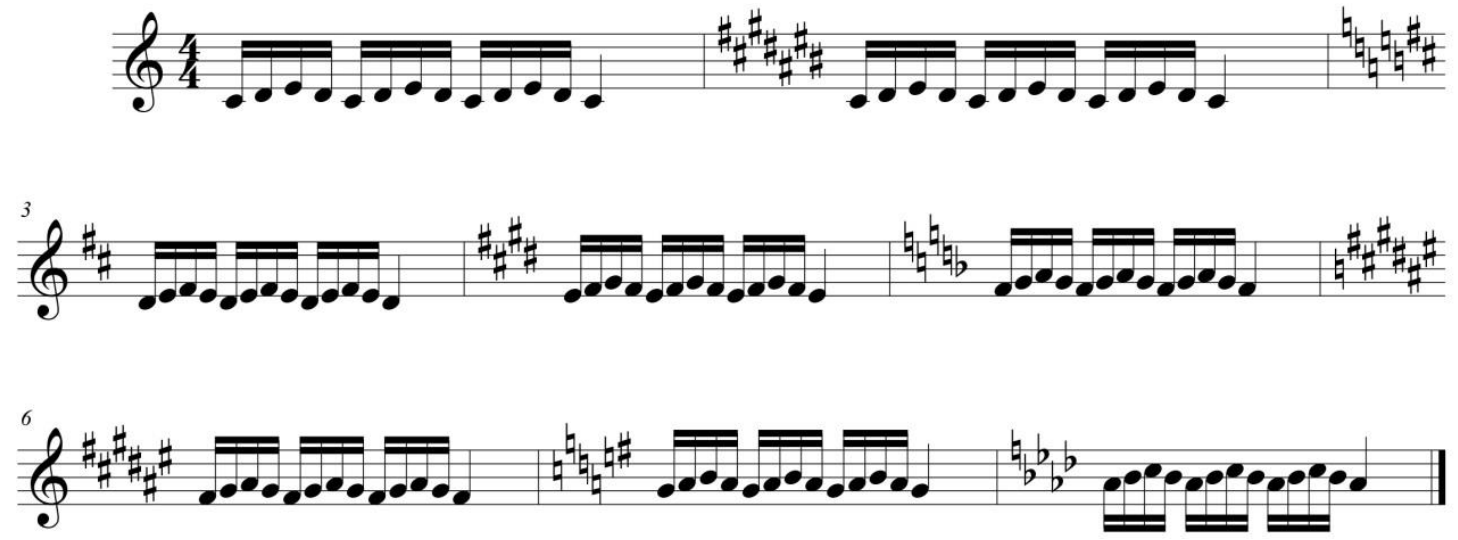

However, if we take the(quarters) of the tone for all the possible degrees of the exerciser, and perform the exercises on them in succession, the exercise will become more effective than the aforementioned classic exercise. And we have done this experiment over a period of nearly two decades, and we noticed the difference in the exerciser with quarters of the tone, differentiating him from the one who exercises in the classical way with the 12 chromatics in one octave, and the secret is that the exercise is performed in the classical way, for example, on 12 "half tones" and divides the two strings in the larynx to 12 points, while in performing it on the quarters of the tone, the larynx is divided into 24 (in 1 octave) movement points, that is, a double number, and this is what gives the larynx greater flexibility, and the proof of that is in the abilities of the Arab singers in the "vocal melisma" that surpass the international opera singers, As this art requires, in addition to talent, to operate the larynx as many dividing points as possible. Here is an example of what we tested with excellent results.

In this way, the number of laryngeal points in the laying of the tunes becomes two times more than what is in the international classical method. And this exercise is performed only on a modern electronic instrument that has a piece of conversion 
(Converter) for all degrees into a "quarter of the tone" like what is called today an oriental keyboard - organ, and not on another instrument, so that the exerciser can perform his exercises with the accompaniment of the mentioned instrument from his teacher or another player who masters this work.

\section{Discussion}

All of the above topics related to the human voice, i.e., the human voice, can be summarized in a short review containing the important issues addressed under this document. We see that there are many topics that have not been researched, studied, or even contemplated.

We have worked on many new topics that had not been researched before us. Over the course of three decades in university teaching, we discovered these scientific problems related to the human voice and developed solutions, curricula and practical exercises for them. The most important of these topics:

1. The human voice is a smart machine.

2. Mechanical voice production and practice it.

3. The elements included in the basic structure of the human voice and putting them in the test and then in the application.

4. The expressive act of the human voice, which includes all kinds of vocal arts: speech and narration, news reading, oratory, voice acting, local singing, operatic singing, prose and poetic recitation and diction.

5. Our new podcast called "Salim Saad Non-Music Podcasting System".

6. Composing audio projects for the so-called "audible scene" on radio.

7. Implementation of combined works between singing and all its types and purely representative scenes.

As for the research on the problems of the human voice, which have not been discussed to this day, we propose several topics that are subject to study, research and scientific conclusion to put them in the service of science and the applied professions associated with them, and we list them as follows:

1. Vocal linguistic melody and its intonation degrees.

2. From singing to all kinds of vocal expression by searching and comparing.

3. Doctrines of modern and oldest music in the way of sound research and its merits.

4. Audio and music notation systems from ancient times until today.

5. The human voice is the basis of criteria for evaluating musical instruments. 


\section{Conclusion}

We have completed a scientific presentation under the title "Professional Voice", meaning the human voice, which may have many real types, each of which has its own characteristics, considering that the human voice is the mirror of human feeling as it changes with each of the psychological states of humans, and the most important types of human voice states are the following:

1. Innate (disorganized) voice,

2. The inherited voice and the acquired voice,

3. The primitive voice and the civilized voice,

4. Inherited primordial voice,

5. Civilized imitated voice,

6. Studied acquired voice,

7. Popular voice,

8. Academic Voice.

Each of the mentioned characteristics of the human voice deserves to become a scientific subject for research and anatomy in order to clarify the civilizational signs of each people through the human voice, which differs between one person and another, between one group and another, between one village and another, and between one people and another even if they all speak. one language. And we want to develop rare studies on the human voice, hoping that the readers of this research will focus on choosing topics for study and research from the topics of the human voice.

\section{References:}

Al-Farabi, Abu Nasr. The Great Music Book. Investigated by Ghattas Abdel-Malik. Revised and fore worded by Dr. Mahmoud Ahmed Al-Hafni. Cairo: Dar AlKateb Al-Arabi for Printing and Publishing. (in Arabic)

Al-Ma'arri, Jinni, Ibn \& Al-Khaymi, Ibn (1981). Three Messages in the Language. Investigated by Dr. Salah Al-Din Al-Munajjid. Beirut: Dar Al-Kitab Al-Jadeed. (in Arabic)

Anatomy of the human body (1979). In: the Higher Education Curriculum for Medicine. Moscow. (in Russian)

Cande, Roland De (1970). Dictionnaire de musique. France: Édition du Seuil, Microcosme. (in Russian)

Cross, Richard (1991). La voix dévoilée. Paris: Romillat. (in Russian)

Jawhari, Tantawi. Arabic Music. (in Arabic) 
Lang, Paul Henry (1985). Music in Western Civilization. Arabization of Dr. Ahmed Hamdi Mahmoud. Review d. Hussein Fawzi. Cairo: General Egyptian Book Organization. (in Arabic)

Lloyd, Séton (1984). L'archéologie de la Mésopotamie. Moscou: Naouka. (in Russian)

Miller, Richard (1986). La structure du chant. Macmillan. (in Russian)

Rodeleux, Louis-Jacques (1974). Trouver sa voix. Paris: Seuil. (in Russian)

Saad, Salim (2016). The Encyclopedic Book on Music an Audio Art in Lebanon and Worldwide. Beirut. (in Arabic)

Saad, Salim (2000). The Human Voice - Genius Instrument. Beirut. (in Arabic)

Sina, Abu Ali Ibn (1333). The reasons for the occurrence of the letters. Tehran. (in Arabic)

Sons et musique. Journal annuel "Pour la science". Édition française de. (in Russian)

Soviet Music Encyclopedia (1973). In 6 parts. Moscow. (in Russian)

Soviet Musical Encyclopedic Dictionary (1959). Moscow. (in Russian)

The Torah (from the Old and New Testaments) (in Arabic)

Wardi, Mikhail Khalil Allah (1964). A Tour in the Science of Arabic Music. Baghdad. (in Arabic)

Western Musical Literature. Part One (1978). In: the Higher and Intermediate Educational Curriculum. Moscow. (in Russian).

\section{Notes and clarifications}

[1] A hymn means reading religious texts in a simple melody, perhaps to the same extent, and this does not coincide with singing, but rather is part of it. We can consider intonation to be reading or "Tajwid" because of excellent linguistic reading on a certain musical note or two-stage exchange with a long sound and a period of time. And intonation or, in the same way, "Tajwid" is actually a complete and regular linguistic reading of the rhythmic balance of speech with the integration of linguistic sounds of the larynx and linguistic letters.

[2] A degree in the comparison list means moving along the absolute scale of phonemes, and in intonation or "Tajwid" there is no need to move between degrees, since reading exercises can only be performed on one phoneme or note without the need for melodic expression in the voice, that is, tonal expression, so intonation or "Tajwid" can be performed in one position or one note too. Unlike reading or anthem of the Quran or singing.

[3] The stressful effort of voting at a young age, that is, before puberty, prevents the throat from growing, and this is similar to the practice of lifting weights for the Barbell children when they become dwarves. Therefore, in opera and vocal lyric 
education it is forbidden to continuously train in the human voice until the childbearing age of both sexes is reached, in order to ensure the integrity of throat growth.

[4] A tuned melody is that which is proportional to the musical scale and musical notes, while an uncontrolled melody is a change in pitch that does not correspond to these scales and tones. However, both together: a disciplined melody and an uncontrolled melody are included equally in the phoneme expression, but in two different proportions and with two different descriptions. Singing or melody takes about $10 \%$ of a person's vocal expression, while a non-singing melody takes up the remainder and is at least $90 \%$. Conversely, in terms of characterization, a sung melody, which is small in proportion, is based on the science of music and its disciplined applications. As for the unsung melody, the largest share of which until today does not depend on any scientific or blog systems and application systems in general, if there weren't any constant attempts to control and organize in all parts of the world, and from this study we, publicly, agree with some success if God gives.

[5] Rhythms branch out from each other. That is, some of the basic ones, which directly follow from language segmentation, diverge in their evolution into several rhythms, which have their own clicks and forms, which somewhat distinguish them, and sometimes completely, from the basic ones. 